\title{
Narın Çikolata Üretiminde Kullanımı
}

\section{Ali YILDIRIM ${ }^{1}$, Öznur TOĞRUL ${ }^{1}$, Seda ÇETíN ${ }^{1}$, Halime ÖĞRETMEN ${ }^{1}$, Pelin SARI ${ }^{1}$ Ibrahim HAYOĞLU ${ }^{*}$}

\author{
${ }^{1}$ Harran üniversitesi, Ziraat Fakültesi, Gıda Mühendisliği Bölümü, Şanlıurfa \\ *Sorumlu yazar: ihayoglu@harran.edu.tr
}

\begin{abstract}
Öz
Bu çalışmada son yıllarda popülerliği artan narın çikolata üretiminde kullanılabilirliği araştırılmıştır. Üretimde kullanılacak çikolata tipini ve ilave edilmesi gereken nar ve jöle miktarını belirlemek amacıyla çeşitli ön denemeler yapılmıştır. Üç aylık depolama süresince duyusal ve objektif değerlendirmeler yapılarak, üretilen narlı çikolatanın tüketici tarafından kabul edilebilirliği araştırılmıştır. Yapılan değerlendirmeler sonucunda narlı çikolatanın büyük beğeni kazandığı ve tercih edilen bir ürün olacağı, ortalama \%17.5 oranında nar tanesi veya \%32.3 oranında nar jölesi ilave edilen narlı çikolataların daha çok kabul gördüğü tespit edilmiştir.
\end{abstract}

Anahtar kelimeler: Çikolata, Jöle, Nar, Duyusal.

\section{Usage of Pomegranate in Chocolate Production}

\begin{abstract}
In this study, it was searched whether the use of the pomegranate whose popularity has increased at last years is appropriate for chocolate production. By conducting various preliminary experiments on the purpose determining the type of chocolate which will be produced and the amount pomegranate and jelly that will be added. It was searched whether chocolate with pomegranate which was produced through emotional and objective assesments will be acceptable for consumers, during 3 months for storing in certain periods. According to consumer surveys, and the sensory assessments by consumers of pomegranate chocolate with a product that can be accepted is concluded. Also, $17.5 \%$ pomegranate and $32.3 \%$ pomegranate jelly added chocolate was preferred by consumers.
\end{abstract}

Anahtar kelimeler: Chocolate, Jelly, Pomegranate, Sensory.

Giriş

Nar (Punica granatum) Punicaceae familyasından çok yıllık bir bitkidir. Narın kültür tarihi oldukça eskilere uzanmakta olup çeşitli kaynaklarda yetiştiricilik geçmişinin 5000 yıl öncesine dayandığı belirtilmektedir (Glozer ve Ferguson, 2008; Ünal, 2011; Oğuz ve ark., 2011). Türkçede kullanılan "nar" kelimesi Farsça'dan dilimize geçmiştir. Latince ismi ise Punica granatum'dur. Nar'ın anavatanının İran,
Hindistan ve Pakistan olduğu bildirilmektedir. Günümüzde İran başta olmak üzere Çin ve Hindistan'da yetiştiriciliği yapılmaktadır. Türkiye, nar üretimi bakımından 4 . sırada yer almaktadır. Pakistan, Azerbaycan ve İspanya ise diğer önemli üretici ülkelerdir (Işık ve ark., 2006). Narın yüksek adaptasyon kabiliyeti, dikildikten 3-4 yıl sonra meyve vermeye başlaması, ağacının ve meyvesinin dayanıklıı̆ı ve meyvesinin 
yararlarının yeniden keşfedilmesiyle üretimi gün geçtikçe yaygınlaşmaktadır (Anonim, 2008a).

Türkiye'de nar üretiminin $\% 61.8^{\prime} \mathrm{i}$ Akdeniz, \%23.3'ü Ege ve \%9.1'i de Güneydoğu Anadolu Bölgesi'nde yapılmaktadır.

Ülkemizdeki nar üretimi 1980'li yılların başlarında üretim miktarı 40000 tonu dahi bulmuyordu (1980'de 36000, 1985'te 33000 ton). İlerleyen yıllarda küçük çaplı artışlarla nar üretimi 1987 'de 44000 'e, 1994 'te de 58000 'e ve 2000 'de de 59000 tona yükselmiştir. 2003 yılına gelindiğinde nar üretiminde bir önceki yıla göre kayda değer bir artış gözlenmiş ve sayısı 4290000'a ulaşan nar ağaçlarından toplam 80000 ton ürün elde edilmiştir (Tüik, 2012).

Son yıllarda yapılan çalışmalar neticesinde antioksidan içeriğinin yüksekliği yanında narın kanı sıvılaştırdığı, kötü huylu kolesterolü düşürdüğü, Alzheimer ve kalp rahatsızlıkları tedavisine yardımcı olduğu, bazı kanser türlerine karşı vücuda direnç sağladığı; suyunun ise kandaki parametrelerde olumlu değişikliklere sebep olduğu anlaşılmıştır (Oğuz ve ark., 2011; Alper, 2001). Narın özellikle içerdiği antioksidanlar sayesinde vücudun savunma sistemini güçlendirdiği belirlenmiştir. İçermiş oldukları antioksidanlar, polifenolik maddeler ve $\mathrm{C}$ vitamini içeriğinden dolayı fonksiyonel gıdalar grubuna alınmıştır (Acar, 1998). Narın içeriğine ait bazı bilgiler Çizelge 1'de verilmiştir.

Ülkemizde nar taze olarak tüketilmekle beraber bazı ürünlere işlenerek de değerlendirilmektedir. Bu ürünlerin başında son günlerde üretimi ve tüketimi artan nar suyunun yanı sıra yemeklerde ve salatalarda sos olarak kullanılan nar ekşisi gelmektedir. Bunların yanında nar likörü, nar şarabı, nar pekmezi ve nar reçeli gibi ürünlerde üretilmektedir.

Kakao çekirdeği, "Theobroma Cacao" ağacının meyvesidir. Etli, olgun meyvelerin içinden çıkarılan çekirdekler, birkaç gün mayalandırıldıktan sonra güneşte kurutulur ve böylece çekirdekler işlenmeye hazır hale getirilir. Fabrikada temizlenen kakao çekirdekleri kavrulur ve öğütülür. Elde edilen macun görünümündeki SIVI preslenerek kakao ve kakao yağı elde edilir. Ögütülmüş kakao çekirdeklerinin suyla karıştırıması ile kakao içeceği olarak başlayan ve günümüze kadar farklı aşamalardan geçerek geliştirilen çikolata, yaklaşık 3000 yıllık bir tarihe sahiptir.

Çikolata kültürü, Güney Amerika'da kakao ağacı çekirdeğinin önce Mayalar, daha sonra Aztekler tarafından kakaolu içecek olarak hazırlanmasıyla başlamıştır. İspanyol kâşiflerin Amerika kıtasını keşfiyle, kakao içeceğinin önce i̇spanya'ya sonra Avrupa'ya yayılması ile çikolatanın önemli gelişimleri başlamıştır.

Çikolatanın en genel tanımlaması yapıldığında, çikolata, kakao ürünleri ve şeker kullanılarak üretilen bir gıda ürünüdür. Çikolata, süt, süt ürünleri, diğer gıda bileşenleri ve izin verilen katkı ve aroma maddelerinin ilavesi ile hazırlanmaktadır. Çikolataların temel bileşiminde kakao Kuru maddesi, kakao yağı ve şeker bulunur (Kaya ve Şekeroğlu, 2012).

Farklı damak zevkleri, tüketici talepleri ve çikolata kalitesinin artırılmasına yönelik araştırmalar sonucunda, günümüzde farklı çikolatalar üretilmekte ve üretim teknikleri her geçen gün gelişim göstermektedir.

Çikolata, çeşitlerine göre bitter (siyah), sütlü ve beyaz çikolata olarak üçe ayrılır. Her üç çeşit çikolatanın da bileşenleri Çizelge 2'de verilmiştir. Buradan da 
anlaşılacağı üzere tüm çikolata çeşitlerinde kullanılan ortak hammadde kakao yağıdır.

$\mathrm{Bu}$ çalışma ile ülkemizde ve özellikle bölgemizde büyük bir yetiştirme potansiyeline sahip olan narın çikolata üretiminde kullanılması, yeni bir kullanım alanı yaratılması yanı sıra sağlık ve besleme açısından önemli olan iki ürünün birlikte kullanılması ile fonksiyonel bir ürün üretilmiş olacaktır.

Çizelge 1. $100 \mathrm{~g}$ nar tanesinin içerikleri (Anonim, 2006)

Table 1. Contents of $100 \mathrm{~g}$ of pomegranate seeds (Anon., 2006)

\begin{tabular}{lc}
\hline İcerikler & $\begin{array}{c}\text { Miktar (g veya mg) } \\
\text { Quantity (g or mg) }\end{array}$ \\
\hline Protein & $0.05-1.6 \mathrm{~g}$ \\
Yağ & 0.9 g'a kadar \\
Karbonhidrat & $15.4-19.6 \mathrm{~g}$ \\
Lif & $3.4-5.0 \mathrm{~g}$ \\
Kül & $0.36-0.73 \mathrm{~g}$ \\
Kalsiyum & $3.0-12.0 \mathrm{mg}$ \\
Fosfor & $8.0-37.0 \mathrm{mg}$ \\
Demir & $0.3-1.2 \mathrm{mg}$ \\
Sodyum & $3.0 \mathrm{mg}$ \\
Potasyum & $259 \mathrm{mg}$ \\
Karoten & iz miktarda \\
Thiamin & $0.003 \mathrm{mg}$ \\
Riboflavin & $0.012-0.03 \mathrm{mg}$ \\
Niacin & $0.180-0.3 \mathrm{mg}$ \\
Ascorbik asit & $4.0-4.2 \mathrm{mg}$ \\
Sitrik asit & $0.46-3.6 \mathrm{mg}$ \\
Borik asit & $0.005 \mathrm{mg}$ \\
Kalori & $63-78 \mathrm{kcal} \mathrm{g-1}$ \\
\hline
\end{tabular}

\section{Materyal ve Yöntem}

Narlı çikolata üretiminde materyal olarak Şanlıurfa yöresinde ve ülkemizde yaygın olarak yetiştirilen Hicaz Nar çeşidine ait narlar kullanılmıştır. Narlar Şanlıurfa yöresindeki semt pazarlarından temin edilmiştir.

Nar taneli çikolata yapımında piyasadan temin edilen sütlü ve beyaz çikolata kuvertürleri ve silikon çikolata kalıpları kullanılmıştır.

Nar jöleli çikolata yapımında nar jölesi için hızlı jelleşen 150 jel dereceli turunçgil pektini (E440, B\&V-Italy) kullanılmıştır. Şanlıurfa yerel marketlerinden satın alınan çay şekeri kullanılmıştır. Nar tanelerinin kaplanmasında piyasadan temin edilen gam arabik (E414) kullanılmıştır.

\section{Narlı Çikolata Yapımı}

Narlı çikolata üretiminde Şekil 1'de gösterilen işlem sırası dikkate alınmıştır. Şekilden de görülebileceği gibi Hicaz narı sırasıyla yıkama, tane çıkarma ve ayıklama işlemlerine tabi tutulmuştur.

Nar tanelerini Arap zamkı ile kaplama işlemi için, Arap zamkından $5 \mathrm{~g}$ alınarak toz haline getirilmiş ve $100 \mathrm{~g}$ su ile ısıtılarak çözelti oluşturulmuştur. Oluşturulan çözeltinin içerisine nar taneleri atılmak suretiyle kaplama işlemi yapılmıştır. Daha sonra kaplanan nar taneleri geniş bir tepsiye dökülerek kurumaya bırakılmıştır. Kaplama işleminin tamamlanmasının ardından çikolata üretiminde kullanılmıştır. Nar jölesi üretiminde 1/1 oranında nar suyu ve şeker kullanılmış olup jelleşmeyi sağlamak üzere karışıma yaklaşık \%0.1 oranında pektin ilave edilmiştir. 
Çizelge 2. Çikolata çeşitlerinin kuru madde miktarı üzerinden hesaplanan bileşenleri (\%)(Anonim, 2003)

Table 2. Constituents of chocolate types in dry bases (\%)(Anon., 2003)

\begin{tabular}{|c|c|c|c|c|c|c|}
\hline Çikolata Tipi & $\begin{array}{c}\text { Toplam Kakao } \\
\text { kuru maddesi } \\
\text { Total Cocoa dry } \\
\text { matter }\end{array}$ & $\begin{array}{c}\text { Yağsız Kakao } \\
\text { kuru maddesi } \\
\text { Oil-free Cocoa } \\
\text { dry matter }\end{array}$ & $\begin{array}{c}\text { Kakao yağı } \\
\text { Cocoa } \\
\text { butter }\end{array}$ & $\begin{array}{l}\text { Toplam } \\
\text { Yağ } \\
\text { Total } \\
\text { fat }\end{array}$ & $\begin{array}{l}\text { Süt kuru } \\
\text { maddesi } \\
\text { Milk dry } \\
\text { matter }\end{array}$ & $\begin{array}{l}\text { Süt yağı } \\
\text { Milk fat }\end{array}$ \\
\hline Bitter Çiko. & $\geq 35$ & $\geq 14$ & $\geq 18$ & & & \\
\hline Sütlü Çiko. & $\geq 25$ & $\geq 2.5$ & & $\geq 25$ & $\geq 14$ & $\geq 3.5$ \\
\hline Beyaz Çiko. & & & $\geq 20$ & & $\geq 14$ & $\geq 3.5$ \\
\hline
\end{tabular}

Narlı çikolata yapımında ise kalıplama çikolata tekniği (2 cm çaplı) kullanılmıştır. Üretim için sütlü veya beyaz çikolata kuvertürü su banyosunda $45^{\circ} \mathrm{C}$ de eritilmiştir. Eritilen çikolata silikon kalıplara dökülerek kalıplar ağzına kadar doldurulmuştur. Oda sıcaklığında bir süre bekletilen çikolata dolu kalıplar soğutulup ters çevrilerek ince bir çikolata katmanı oluşması için çikolatanın fazla kısmı boşaltılmış ve içerisine nar tanesi, zamklı nar tanesi ve jöle ilave edilerek üzeri tekrar çikolata ile kaplanmıştır. Üretilen çikolatalar paketlenerek (alüminyum folyo) $10 \pm 3^{\circ} \mathrm{C}$ muhafaza edilmiştir.

Uygun koşullarda muhafaza edilen narlı çikolatalar, 30., 60. ve 90. günlerde duyusal ve fiziksel analizlere tabi tutulmuştur.

\section{Üretimde Kullanılan Narın Özelliklerinin Belirlenmesi}

Üretimde kullanılan Hicaz narının bazı özelliklerinin belirlenmesi amacıyla narlar kabuk oranı, meyve suyu oranı, tane oranı, çekirdek oranı, asitlik, pH, suda çözünür kuru madde, 100 tane ağırlığı, tane rengi ve tat gibi özellikler açısından değerlendirmeye tabi tutulmuştur (Hayoğlu ve Türkoğlu, 2005) (Çizelge 3).

\section{Toplam Kuru madde tayini}

Üretilen narlı (tane, zamk kaplı veya jöle formunda) çikolatalarda toplam Kuru madde analizinin, toplam Kuru madde analiz yöntemine uygun olarak yapılmasıdır.

\section{Duyusal Analizler}

Üretilen narlı çikolata örnekleri, Harran Üniversitesi Gıda Mühendisliği Bölümü Öğretim Üyeleri ile Doktora, Yüksek Lisans ve Lisans Öğrencilerinden oluşan toplam 17 kişilik panelist grubu tarafından duyusal değerlendirmeye tabi tutulmuştur. Panelistlerden narlı çikolata örneklerini, renk, koku, tekstür, tat/aroma ve ağızda bıraktığı his bakımından değerlendirmeleri istenmiştir. Değerlendirme 1 en düşük ve 5 en yüksek puan olarak 1-5 arasında puan verilerek yapılmıştır.

\section{Istatistiksel Analizler}

Araştırmada elde edilen bulgular SPSS 16.0 istatistik paket programı kullanılarak varyans analizine tabi tutulmuştur. Örnekler arasındaki farklılıklar ise Duncan çoklu karşılaştırma testi kullanılarak belirlenmiştir. 


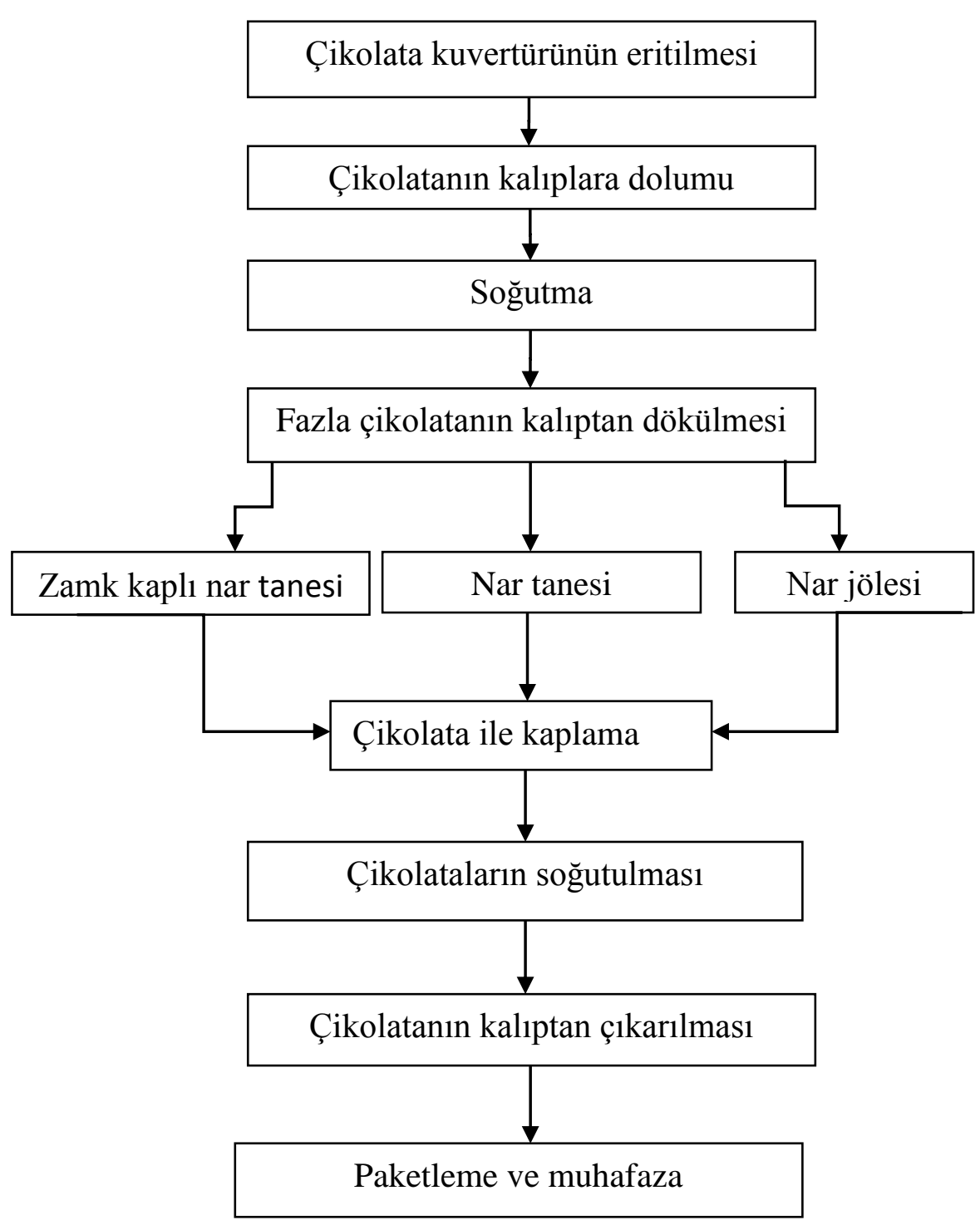

Şekil 1. Narlı çikolata üretim akış şeması

Figure 1. Flow chart of production process of Pomegranate chocolate

\section{Araştırma Bulguları ve Tartışma}

Üretimde Kullanılan Narın Özellikleri

Narlı çikolata üretiminde kullanılan hicaz çeşidi olan narda yapılan bazı ağırlığı sırasıyla yaklaşık \%55.6 ve $0.33 \mathrm{~g}$ civarındadır. Narlarda rengin koyu kırmızı ile bordo arasında değişiyor olması özellikle kaplamada beyaz çikolatanın kullanıldığı durumlarda üründe renk uyumu ölçümler ve bu ölçümlere ait değerler Çizelge 3'te verilmiştir.

Çizelge 3'deki ölçüm sonuçlarına bakıldığında da görüleceği gibi üretimde kullanılan hicaz narında tane verimi ve tane bakımından üstünlük sağlamakta ve albenisini arttırmaktadır. Ayrıca Hicaz narında tadın mayhoş olması, narlı çikolata üretiminde tat dengesi açısından uyumlu olmasını sağlamaktadır. 
Çizelge 3. Hicaz narında yapılan analizler Table 3. Analysis of Hicaz Pomegranate

\begin{tabular}{lc}
\hline Özellikler & Değerler \\
\hline $\begin{array}{l}\text { Kabuk Oranı (\%) } \\
\text { Shell ratio (\%) }\end{array}$ & $44.4 \pm 0.5$ \\
\hline $\begin{array}{l}\text { Meyve Suyu Oranı (\%) } \\
\text { Juice ratio (\%) }\end{array}$ & $39.5 \pm 0.3$ \\
\hline $\begin{array}{l}\text { Tane Oranı (\%) } \\
\text { Grain ratio (\%) }\end{array}$ & $55.6 \pm 0.6$ \\
\hline $\begin{array}{l}\text { Çekirdek Oranı (\%) } \\
\text { Seed ratio (\%) }\end{array}$ & $16.1 \pm 0.2$ \\
\hline $\begin{array}{l}\text { Asitlik (\%) } \\
\text { Acidity (\%) }\end{array}$ & $1.4 \pm 0.1$ \\
\hline $\begin{array}{l}\text { pH } \\
\text { pH }\end{array}$ & $3.6 \pm 0.2$ \\
\hline $\begin{array}{l}\text { Brix değeri (\%) } \\
\text { Brix value (\%) }\end{array}$ & $15.5 \pm 0.1$ \\
\hline $\begin{array}{l}100 \text { Tane Ağırlığı (g) } \\
100 \text { Grain weight (g) }\end{array}$ & $33.2 \pm 0.4$ \\
\hline $\begin{array}{l}\text { Tane Rengi } \\
\text { Grain color }\end{array}$ & Kırmızı-Bordo \\
\hline $\begin{array}{l}\text { Tat } \\
\text { Taste }\end{array}$ & Mayhoş-Tatlı \\
\hline
\end{tabular}

Üretilen Çikolatalarda Toplam Kuru madde Miktarı

Üretilen narlı çikolata örneklerinde toplam Kuru madde analizi yapılmıştır. Yapılan analizden elde edilen bulgular çizelge 4'de verilmiştir.

Çizelge 4'de verilen analiz sonuçlarından da anlaşılacağı gibi nar jölesi kullanılarak üretilen sütlü ve beyaz çikolatada toplam kuru madde oranı daha yüksektir. Bunun sebebi nar suyunun jöle haline getirilerek kuru madde içeriğinin yükseltilmesidir. Toplam kuru madde oranının yüksek olması ürünün depolanma süresinin uzamasına ve küf gelişiminin olmamasına yardımcı olarak depolama açısından da yarar sağlamaktadır.

Çizelge 4. Üretilen Narlı Çikolata Örneklerinde Toplam Kuru madde Değerleri (\%)

Table 4. Values of total dry matter (\%) of Pomegranate chocolate

\begin{tabular}{lll}
\hline Narlı & Çikolata & Örnekleri \\
\hline $\begin{array}{l}\text { Nar Taneli } \\
\text { Sütlü Çikolata }\end{array}$ & $\begin{array}{l}\text { Nä Jöleli } \\
\text { Çikolü }\end{array}$ & $\begin{array}{l}\text { Nar Jöleli } \\
\text { Beyaz Çikolata }\end{array}$ \\
\hline $92.55 \pm 0.07$ & $97.28 \pm 0.04$ & $97.28 \pm 0.05$ \\
\hline
\end{tabular}

\section{Duyusal Analizler}

Üretilen nar taneli sütlü çikolata ile nar jöleli sütlü ve beyaz çikolata, farklı damak zevkine ve yemek kültürüne sahip, 17 gönüllü panelist tarafından duyusal olarak değerlendirilmiştir. Duyusal değerlendirmede üretimi yapılan narlı çikolataların renk, koku, tekstür, tat/aroma, ağızda bıraktığı his özelliklerine bakıımış ve puanlama en yüksek 5 olmak üzere $1^{\prime}$ den 5 'e doğru yapılmıştır.

Çizelge $5^{\prime}$ de de görüldüğü gibi panelistler tarafından yapılan duyusal değerlendirme puanlamasına göre renk, koku ve tat/aroma bakımından en yüksek puanı her ne kadar nar jöleli beyaz çikolata almış olsa da tüketim ve tüketici kabul edilebilirliği açısından genel olarak nar jöleli sütlü çikolata en çok tercih edilen narlı çikolata örneği olmuştur. 
Çizelge 5. Narlı Çikolataların Duyusal Değerlendirme değerleri

Table 5. Sensory analysis of Pomegranate chocolate

\begin{tabular}{lccc}
\hline & Narlı & Çikolata & Örnekleri \\
\hline Değerlendirme Kriterleri & Nar Taneli Sütlü Çikolata & $\begin{array}{c}\text { Nar Jöleli Sütlü } \\
\text { Çikolata }\end{array}$ & $\begin{array}{c}\text { Nar Jöleli Beyaz } \\
\text { Çikolata }\end{array}$ \\
\hline Renk & $4.53 \pm 0.03$ & $4.71 \pm 0.02$ & $4.82 \pm 0.02$ \\
Koku & $3.65 \pm 0.05$ & $3.65 \pm 0.03$ & $3.88 \pm 0.04$ \\
Tekstür & $3.53 \pm 0.03$ & $4.06 \pm 0.01$ & $3.94 \pm 0.07$ \\
Tat/Aroma & $3.88 \pm 0.04$ & $4.06 \pm 0.02$ & $4.11 \pm 0.02$ \\
Ağızda Bıraktığı His & $4.82 \pm 0.03$ & $4.00 \pm 0.04$ & $4.71 \pm 0.01$ \\
Toplam & $20.41 \pm 0.04$ & $20.48 \pm 0.03$ & $21.46 \pm 0.04$ \\
\hline
\end{tabular}

\section{Sonuçlar}

Yapılan değerlendirmeler sonucunda narlı çikolatanın tüketiciler tarafından kolay kabul edilebilir bir ürün olabileceği, nar jöleli sütlü çikolatanın, nar taneli sütlü çikolata ve nar jöleli beyaz çikolataya göre daha çok beğeni aldığı görülmektedir. Ancak zamkla kaplı nar taneleri kullanılarak üretilen narlı çikolatanın oda koşullarında 30 gün depolanmasının sonucunda çatlama ve küflenme görülmüştür. Deneme aşamasında gözlemlenen bu olumsuzluklar sonucunda zamkla kaplanan nar tanelerinin üretimde kullanılması işlemi sonlandırılmıştır.

Ürünün buzdolabında üç ay boyunca depolanması sırasında 30, 60 ve 90 günlük periyotlarda yapılan değerlendirmelerde duyusal özelliklerinde herhangi bir olumsuzluğa rastlanılmamıştır. Daha ileriki çalışmalarda uygun muhafaza koşullarının yanı sıra koruyucu maddelerin kullanımı da göz önünde bulundurulduğu takdirde bu sürenin daha da uzatılabileceği düşünülmektedir.

\section{Kaynaklar}

Acar, J., 1998. Gıda Kimyası. Edidör: İlbilge Saldamlı, Hacettepe Üniv. Yayınları, Ankara.
Alper, N., 2001. Nar Suyu Üretimi Üzerine Araştırmalar. Doktora Tezi, Hacettepe Üniversitesi Fen Bilimleri Enstitüsü, Ankara, 172s.

Anonim, 2003. Türk Gıda Kodeksi Çikolata ve Çikolata Ürünleri Tebliği, Tebliğ No:2003/23, Ankara.

Anonim, 2006. Hasad Bitkisel Üretim Dergisi, Şubat 2006, Sayı:249.

Anonim, $2008 a$. ttp://www.meyed.org.tr/content/fil es/bulten/meyedsayi2nisnmayishazir .pdf

Anonim, 2012. www.tuik.gov.tr. Erişim tarihi: 05.010.2012.

Glozer, K., Ferguson, L., 2008. Pomegranate Production in Afghanistan. UCDAVIS College of Agricultural \& Environmental Sciences, 32s.

Hayoğlu, ì., Türkoğlu, H., 2005. Meyve sebze teknolojisi laboratuvar ders notları. HRÜ-Ziraat Fakültesi, Şanlıurfa.

Işık, E.A., Yazıcı, K., Şahin, A., Kaya, N., 2006. Nar'ın Türkiye ve Dünyadaki Durumu, Batı Akdeniz Tarımsal Araştırma Enstitüsü, http://www.batem.gov.tr/ürünler/m eyvelerimiz/nar.

Kaya, A., Şekeroğlu, G., 2012. Çikolata, Standart Dergisi, 604: 22-31. 
Oğuz, H.ì., Ukav, i.., Eroğlu, D., 2011. 'Güneydoğu Anadolu Bölgesi'nde Nar (Punica granatum L.) Üretimi ve Pazarlaması', GAP VI. Tarım Kongresi, 09-12 Mayıs, 108-112s. Şanlıurfa.

Ünal, A., 2011. Bahçe Tarımı- II., Yumuşak Çekirdekli Meyve Türleri ve Nar Yetiştiriciliği, T.C. Anadolu Üniversitesi Yayını No:2358, 16-19s.

Eskişehir. 